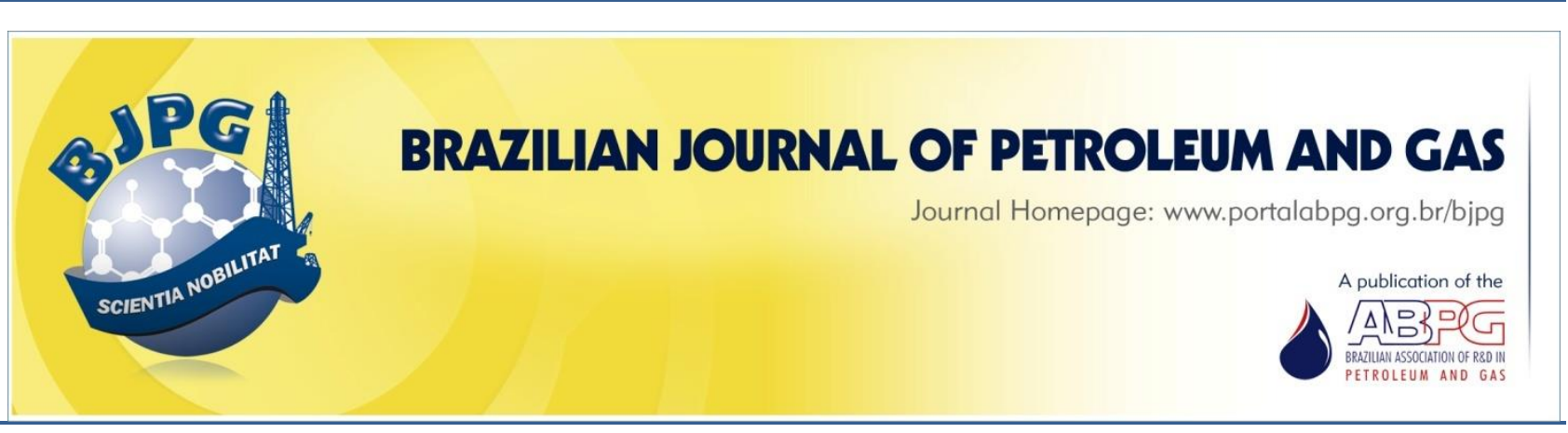

\title{
OPTIMIZATION OF A PETROLEUM FRACTIONAL DISTILLATION COLUMN USING DISTOP CALIBRATION AND STATISTICAL METHODS
}

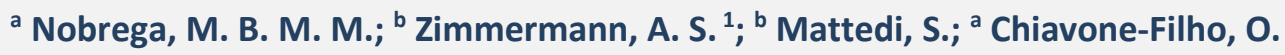 \\ a Federal University of Rio Grande do Norte, Chemical Engineering Graduate Program, Natal - RN, Brazil \\ ${ }^{b}$ Federal University of Bahia, Chemical Engineering Graduate Program, Salvador - BA, Brazil \\ Received: 08.08.2020 / Revised: 04.11.2020 / Accepted: 08.11.2020 / Published on-line: 07.01.2021

\begin{abstract}
Distillation columns are important separation equipment that comprise most of the investment needed in a petroleum refining plant. Utilities and energy demands, though, are a concerning factor in the current economic and environmental scenario. The present work proposes a methodology to optimize the energy consumption of a crude oil distillation column using the Distop Calibration technique that allows faster convergence than the Tray-to-Tray method. The methodology presented involves process simulation, sensitivity analysis, factorial design, and the use of response surface methodology. Results show that it is possible to achieve significant gains by changing feed temperature and rectifying vapor flow, causing a relevant reduction in energy consumption. Hence, the methodology can be used as an optimization tool to increase energetic efficiency.
\end{abstract}

\section{KEYWORDS}

optimization; distillation; petroleum; Distop calibration; response surface methodology

\footnotetext{
${ }^{1}$ To whom all correspondence should be addressed.

Address: Federal University of Bahia, Chemical Engineering Graduate Program, R. Prof. Aristides Novis, 2, Federação, Salvador BA, Brazil

ZIP Code: 40210-630 | Phone number: +55(71) 99348-7869 | e-mail: alexandre.santarem@ufba.br doi:10.5419/bjpg2020-0017
} 


\section{INTRODUCTION}

Global demand for energy is in constant increase, while the energetic matrix is composed mostly by fossil fuels, which have limited availability. Hence, it is mandatory the development and application of more energetically efficient technologies in substitution to classic methods (Szőke-Kis et al., 2014).

The expenses related to the use of a chemical process come mostly from separation and purification processes. Among those processes, the distillation stands out as one of the most important and widely used in chemical and petrochemical industry (Javaloyes-Antón et al., 2013). In a petroleum refinery, distillation importance becomes even more flagrant, since many of the processes that will generate commercial products are downstream to the distillation, and their feeds are streams exiting the column (Gu et al., 2015; Sousa et al, 2015).

Opposed to the wide utilization of distillation in plants and its advantages, this operation has some relevant inconveniences in its application, mainly high capital and operation costs. These inconveniences are related to the installation of huge equipment and low energetic efficiency, respectively. It is estimated that $40 \%$ of all energy used in chemical process industry and 95\% of that used in separation processes are destined to distillation (Kiss, 2014).

Besides, distillation column and associated systems operation are even more highlighted in decision-making on production planning and operations management, since small changes in the employed conditions can result in huge financial variations, making well-reasoned decisions mandatory to the success of the plant (Motlaghi et al., 2008).

Being a process with a history of several decades of application in industry, the distillation is well-developed and described in theoretical and mathematical terms, making it easier to establish design and operation that are safe and reliable (Kim et al., 2013; Szőke-Kis et al., 2014). Fundamental models to predict the efficiency of distillation are available in the literature, for both packed and plate columns. They are the mathematical representation of hydraulic and mass transport phenomena. In association, simulation techniques have been widely used in the industrial environment for the last two decades. During this period, there has been a huge increase in the availability and application of computational simulations by engineers. A myriad of rigorous, statistical and simplified models has been developed and applied in complex columns simulations. However, to corroborate such models, it is necessary to have operational or experimental data from the distillation column in the plant (Ochoa-Estopier et al., 2013; Taqvi et al.; 2016; Yang \& Chuang, 2000).

Experimental planning is a group of mathematical and statistical techniques used to develop, improve, and optimize processes. It can also be used to evaluate the relevance of the effects of several factors in the system response, even when interactions between them are present (Mahdi et al., 2008). For studies involving a large number of experiments, it is possible to use the factorial design, which combines levels of two or more factors, making it possible to determine the interactions between studied variables and their combined effect on a response. This methodology reduces time and effort spent in the process, as it can obtain results that represent the interest region with fewer experiments (Mahdi et al., 2008; Montgomery \& Runger, 2003; Rodrigues lemma, 2005).

Another methodology which, associated with the factorial design, has been applied successfully to solve optimization problems is the response surface methodology (RSM). It consists of a group of mathematical and statistical methods that allows the construction of response surfaces through the generation of a mathematical model. These surfaces represent the behavior of a response as a function of input variables graphically. Studying them allows determining the optimal conditions of a process (Souza et al., 2016). Factorial design can be used to reduce the amount of experiments needed to obtain the data used in the construction of response surfaces.

In the present work, the energy consumption of a petroleum fractionation unit in a refinery in the Northeastern region of Brazil was optimized with the help of process simulation, factorial design, and RSM. The calibration of an atmospheric distillation column in the simulation environment was done in an attempt to achieve a 
trustworthy representation of the real one, and to allow the energetic optimization steps. The method selected for the calibration was the Distop Calibration, from the commercial simulator Petro-SIM, provided by KBC Advanced Technologies; a robust method that allows a faster convergence than the Tray-to-Tray method. It performs the calculations of the fractionation model for each column section, while Tray-to-Tray does it for every stage. Using the stage efficiency and other constants, it is possible to adjust the simulated column performance to match those found in the plant and provide the actual product streams (Camões, 2014; KBC Advanced Technologies, 2017). Being a simplified model of convergence that requires less time, it is possible to use the Distop method to simulate refineries that do not require high precision and/or when the number of simulations to be performed is very high.

After the calibration, the simulation was used, with the aid of factorial design, to provide data for generating models to represent energy consumption and product quality as a function of manipulated variables. These models allowed to generate response surfaces and to optimize process energy consumption.

Furthermore, this work also focused in clarifying the calibration procedure using the Distop Calibration, as this method, though useful and flexible, is still not widely found in literature. To the best of the authors' knowledge, there are no works applying this calibration methodology to atmospheric distillation described in specialized literature.

\section{METHODOLOGY}

\subsection{Calibration}

The products from the side draws of the studied distillation are, from the heaviest to the lightest, heavy diesel (HD), light diesel (LD), and kerosene (KE). The bottom product is the reduced crude oil (RCO) and the top products are heavy naphtha (HN), natural gas, and water. The condenser used is partial and a heat stream $Q$ is removed at the top condenser. There are also two pump-around refluxes. Figure 1 shows a simplified diagram of the crude distillation unit (CDU), according to which the simulation was performed.

First, we checked the plant stability during the period of data acquisition. The standard deviation of each variable was compared to a benchmark provided by the company that operates the column. Under those values, the process can be considered stable. The values were obtained using the software Plant Information (PI), which registers the values measured by the control instruments of the plant. This step is important to ensure that the data collected is a good representation of the regular plant operation.

Having the operation data of flow and distillation curves of the products during a stable operation period, it is possible to characterize the feed entering the column. Such feed has an unknown composition, since it undergoes processes before reaching the fractionation, like the pre-flash separator, to remove light components. Hence, the Synthesize method from Petro-SIM (version 6.1) was used to synthesize and characterize the feed in the simulation environment, starting from the experimental characterization of the products. There was no laboratory analysis for the reduced crude oil, so its distillation curve and flow were obtained through the Synthesize method using products from vacuum distillation, located downstream in the process. It is noteworthy that the distillation curves of the distillate products present in this work are ASTM D86 curves, while the curve displayed by the reduced crude oil is a TBP curve, as the applicability of the D86 method is restricted to distillate fuels and it is not suitable

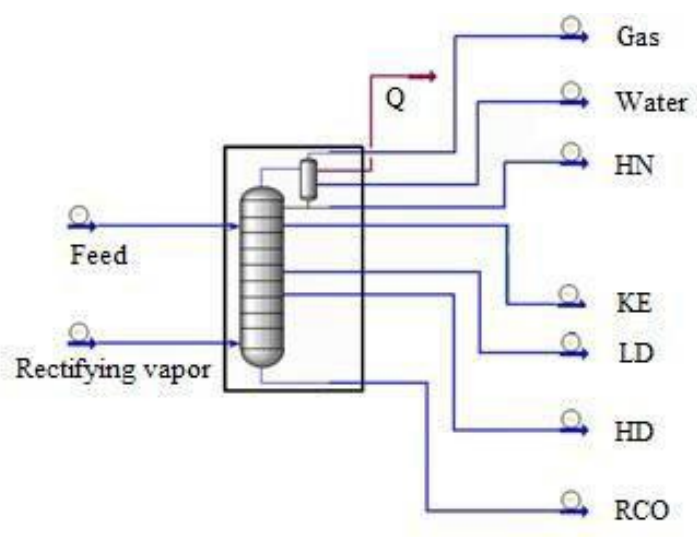

Figure 1. Simplified diagram of the studied crude distillation unit. 


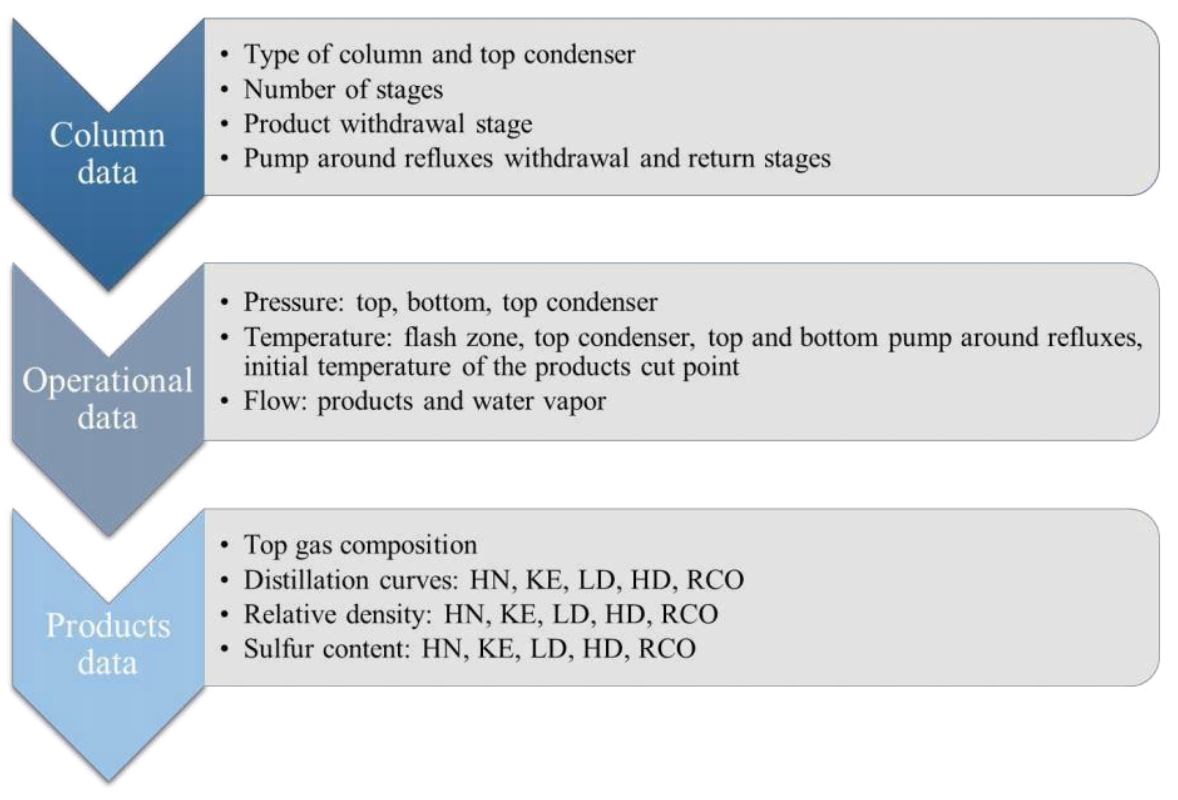

Figure 2. Main variables inserted in simulation environment.

for samples with fairly high amounts of residual material (ASTM International, 2016).

The selected calibration method was the Distop Calibration. The main variables inserted in the simulation environment to perform the calibration are presented in Figure 2.

After that, the calibration itself was done, using the Calibrate menu. Petro-SIM has the option of associating weight to the calibration input data,

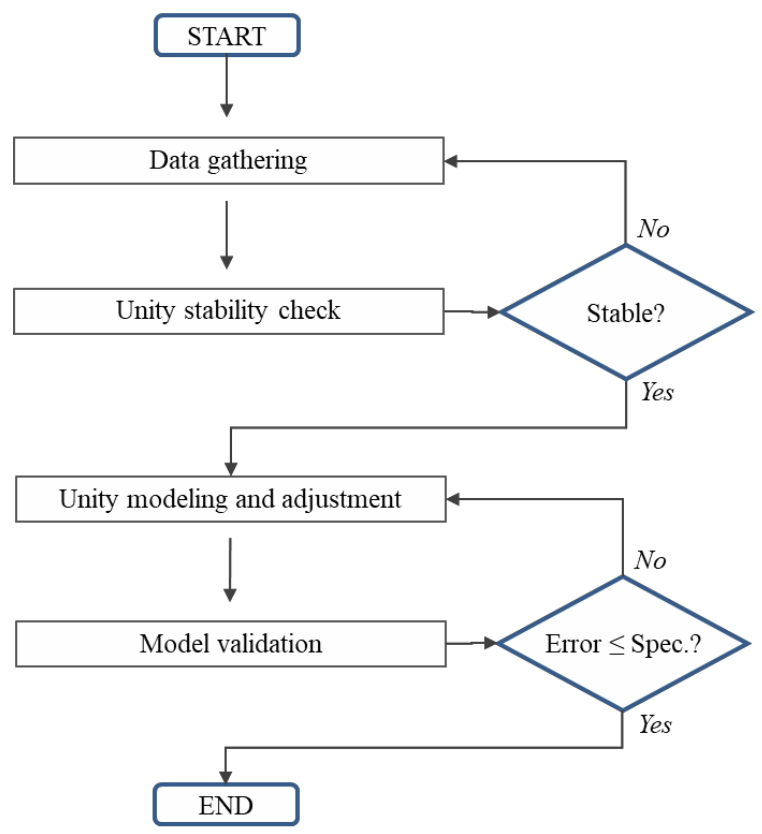

Figure 3. Procedure for generation and validation of the proposed calibration model. providing a higher value to higher weights and adjusting the calibration more as a function of them than the smaller weights. Since all the input data were obtained the same way and with a similar precision, the weight were all kept equal. Furthermore, there was a better agreement with operational data proceeding this way. The method, when finished, provides factors and associates them to the column calibration that adjusts the fractionation.

Standard minimum and maximum values of shape factors in Petro-SIM are 0.8 and 1.2, respectively. In some cases, the factors converged to these boundary values. Thus, the values were redefined to 0.6 and 1.4 , respectively, seeking a better agreement with operational data. It is important to note that these new values are still in agreement with the valid boundaries proposed by the method, according to Petro-SIM user's guide (KBC Advanced Technologies, 2017). Then, the procedure was repeated.

Finally, to validate the obtained model, simulated distillation curves and properties of the products were compared to those obtained in laboratory. Figure 3 represents the steps followed to generate and validate the proposed model.

\subsection{Sensitivity analysis}

This part of the work identifies the optimal operational conditions, minimizing the energy consumption in the top condenser and maintaining 
products' specifications. The goal is to minimize the condenser's heat duty. Products' quality were also evaluated through their distillation curves.

The first step of the optimization was the sensitivity analysis, to evaluate how the independent variables selected affect condenser heat duty and product quality. This analysis was done using the direct method, changing each variable individually and observing the response variation with the aid of the simulation.

Independent variables were selected from the operational experience and the analysis of documents and unit control system. This decision was made considering process restrictions, such as the integration of certain streams with other processes in the refinery, and trying to avoid losses in other areas. Thus, the selected variables were feed temperature and rectifying vapor flow. The temperature variation was carried out from 359 to $375{ }^{\circ} \mathrm{C}$, due to the installed instruments and equipment operational limits. In a similar way, the studied range for the vapor flow was from 280000 to $360000 \mathrm{~kg} \cdot \mathrm{d}^{-1}$.

\subsection{Factorial design}

After the sensitivity analysis, a factorial design was done to help define which simulations would be performed to evaluate the cross influence of the variables in the response, i.e. the condenser heat duty and in product quality. The design with two factors and three levels was chosen. This decision was motivated by its simplicity and its efficiency modeling response surfaces. Table 1 shows the selected variables levels for the factorial design.

\subsection{Determination of the mathematical model}

Simulation results were used in the construction of a mathematical model to represent the relationships between independent variables and responses. To simplify the models, Pareto charts were used. They allow to identify the variables with low significance more easily. Thus, variables that do not affect responses significantly were removed from the model. Using the STATISTICA software (version 7.0) provided by StatSoft and considering only the factors evaluated as significant, the mathematical models were determined. The models help the analysis and understanding of the process, therefore, contributing to its optimization.

Furthermore, using linear regression, linear equations relating simulated data and model data were determined. From this regression, it is possible to check the agreement between simulation and statistical model. In the ideal case, where the simulated and model data are the same, the angular coefficient of the linear equation will be 1 and the linear coefficient will be 0 .

\subsection{Determination of optimal conditions}

The optimal conditions were determined for 3 different scenarios. For scenario $\mathrm{S} 1$, a limitation in the feed heating furnaces is considered. Operational problems or a change in petroleum quality can cause limitations in the feed heating. Thus, this scenario was considered to determine the optimal conditions when the furnaces have to operate with the lowest furnace heat duty, i.e. with the lowest feed temperature.

For scenario $\mathrm{S2}$, there is low availability of water to produce vapor. Besides the environmental issue involving the water consumption, water availability in the region where the refinery is installed is subject to seasonality, due mainly to rain scarcity, impacting the production greatly. In this scenario, the unit should operate with the lowest heat duty in the reboilers used for vapor production, i.e., the lowest rectifying vapor flow.

Table 1. Variables levels used in the factorial design.

\begin{tabular}{cccc}
\hline Variable & Level (-1) & Level (0) & Level (+1) \\
\hline Feed temperature $/{ }^{\circ} \mathrm{C}$ & 359 & 367 & 360 \\
Rectifying vapor flow $/ 10^{3} \mathrm{~kg} \cdot \mathrm{d}^{-1}$ & 280 & 320 & 360 \\
\hline
\end{tabular}


For scenario S3, no limitations were considered whatsoever. This scenario represents the optimization of the top condenser heat duty without the restrictions presented in scenarios S1 and S2. It is important to say that, for each scenario, the premise that products should be specified was maintained.

Then, using the models developed previously and the non-linear GRG method of the Microsoft Excel Solver, the optimal conditions for S1 to S3 were determined. The full methodology used for the optimization can be seen in Figure 4.

\section{RESULTS AND DISCUSSION}

\subsection{Calibration}

All variables analyzed presented a standard deviation under the benchmark value and, therefore, the stability criteria were obeyed. Hence, it is safe to say that the variables showed in the operational data report are a good representation of the regular plant operation. Table 2 presents the stability check data.

One of the main challenges of modelling and simulating columns for oil separation is that it is very common to not have the composition or even the distillation curve for the feed stream. In this case, not being able to describe the feed correctly would lead to an incorrect calibration and, therefore, a bad representation of the real columns. To solve this issue, the Synthesize method was applied to generate a distillation curve for the feed stream. This method provides the feed distillation curve using products distillation curves.

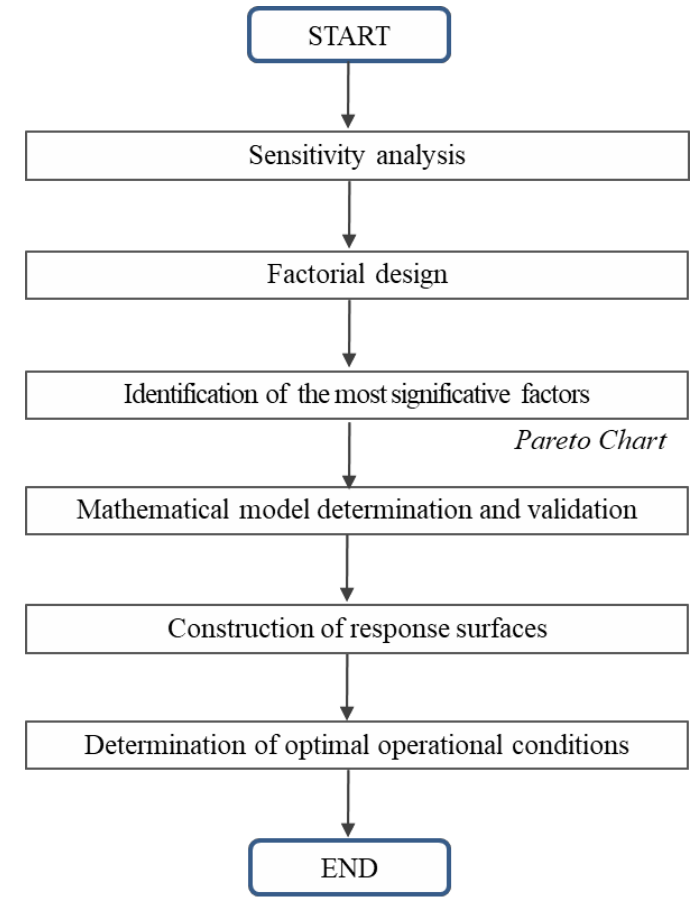

Figure 4. Procedure for the proposed optimization.

Thus, the Synthesize method can be used to overcome the common lack of knowledge about the feed and proceed with the calibration process, as long as products' data are available. It is noteworthy that experimental data for the products are often obtained for quality control. After the application of the Synthesize method, the calibration was performed.

The column calibration generated calibration factors and associated them to the simulated columns, adjusting the simulation to the operational data. Calibration factors obtained are shown in Table 3.

Table 2. Comparison between the benchmark standard deviations and those found when obtaining the samples for laboratory analysis.

\begin{tabular}{ccc}
\hline & Standard deviation & \\
\hline Variable & Benchmark & During stability check \\
\hline Feed flow $\left(/ \mathrm{m}^{3} \cdot \mathrm{d}^{-1}\right)$ & 350.0 & 296.4 \\
Top reflux flow $\left(/ \mathrm{m}^{3} \cdot \mathrm{d}^{-1}\right)$ & 150.0 & 34.8 \\
Pump around flow $\left(/ \mathrm{m}^{3} \cdot \mathrm{d}^{-1}\right)$ & 100.0 & 91.8 \\
Vapor flow $\left(/ 10^{3} \mathrm{~kg} \cdot \mathrm{d}^{-1}\right)$ & 30.00 & 1.89 \\
Temperature $\left(/{ }^{\circ} \mathrm{C}\right)$ & 10.0 & 3.0 \\
Pressure $\left(/ \mathrm{kgf.cm} \mathrm{cm}^{-2}\right)$ & 0.100 & 0.042 \\
\hline
\end{tabular}


Table 3. Calibration factors associated to the column.

\begin{tabular}{cccccc}
\hline Calibration factor & $\mathrm{HN}^{\mathrm{a}}$ & $\mathrm{KE}^{\mathrm{b}}$ & $\mathrm{LD}^{\mathrm{C}}$ & $\mathrm{HD}^{\mathrm{d}}$ & $\mathrm{RCO}^{\mathrm{e}}$ \\
\hline Front shape factor & 1.0000 & 1.4000 & 0.8269 & 1.0180 & 1.1910 \\
Back shape factor & 1.0000 & 0.7051 & 0.9464 & 0.8955 & 1.0460 \\
Volume interchange & 0.0034 & 1.5684 & 2.1029 & 2.7838 & 4.9145 \\
\hline
\end{tabular}

${ }^{a}$ Heavy naphtha; ${ }^{b}$ kerosene; ${ }^{c}$ light diesel; ${ }^{d}$ heavy diesel; ${ }^{e}$ reduced crude oil.

The front shape factor adjusts the points in the beginning of the respective curve, while the back shape factor affects the points in the end of the curve of the lighter adjacent fraction. It is important to note that for fractions that have a bigger curve overlap, these factors can influence a wider range of the curves. A value greater than 1 for these parameters tend to compress the tail of the distillation curve, while values lower than 1 tend to promote the opposite effect. Shape factors, however, work more like a fine tuning of the curves ends and do not influence their middle section as much. To adjust this part of the curves, the section efficiency has greater relevance (KBC Advanced Technologies, 2017).

Another important calibration factor provided by the method is the Volume Interchange, that refers to the curve overlap between adjacent fractions, indicating the fractionation quality. Values close to 0 indicate a perfect fractionation, while high values indicate a low-quality fractionation. The determination of the section efficiency allows the model to predict the distillation with high precision in the curve range from 10 to $90 \%$ of the total volume vaporized. A section related to a product is defined as the part of the column between its withdrawal and the withdrawal of the lighter adjacent product (KBC Advanced Technologies, 2017). After the calibration was done and the calibration factors were associated to the column, the distillation was simulated, providing the products distillation curves. The simulation also predicted the yield of each product and their relative densities with respect to water at $60{ }^{\circ} \mathrm{F}$ (approximately $15.5^{\circ} \mathrm{C}$ or $288.7 \mathrm{~K}$ ). The data obtained allowed us to create graphs with the simulated distillation curves, that were compared to the operational distillation curve, as shown in Figure 5.

It was also possible to quantify the deviations in the model for each point of the simulated curves. The comparison between simulated and

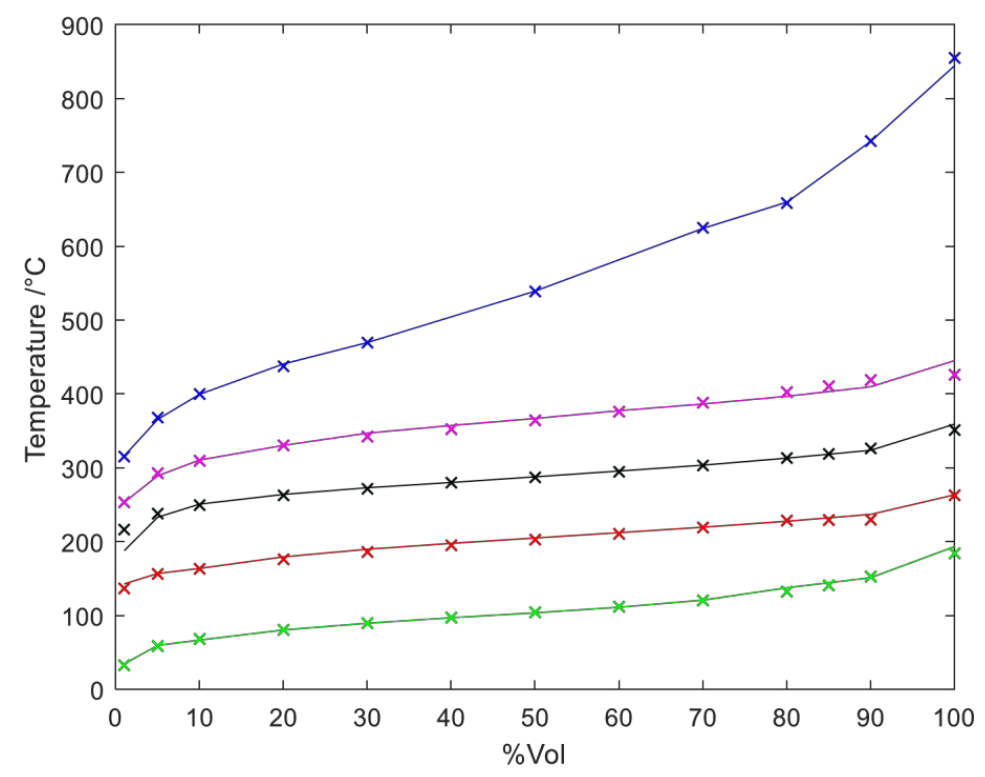

Figure 5. Simulated and operational distillation curves of the products (ASTM D86 for HN, KE, LD and LD; TBP for RCO). Green: HN; red: KE; black: LD; magenta: HD; blue: RCO. Markers refer to operational data. Solid lines refer to simulated data. 
Table 4. Deviations between simulated data after the calibration and operational data. The highlighted data are those which had absolute deviations over the maximum acceptable value, i.e. $10^{\circ} \mathrm{C}$.

\begin{tabular}{|c|c|c|c|c|c|}
\hline \multirow[b]{2}{*}{ Analysis } & \multicolumn{5}{|c|}{ Absolute deviation $/{ }^{\circ} \mathrm{C}$} \\
\hline & $\mathrm{HN}^{\mathrm{a}}$ & $K E^{b}$ & $\operatorname{LD}^{\mathrm{C}}$ & $H D^{d}$ & $\mathrm{RCO}^{\mathrm{e}}$ \\
\hline Type of distillation & ASTM D86 & ASTM D86 & ASTM D86 & ASTM D86 & TBP \\
\hline $1 \%$ vaporized vol. & 1.9 & 6.1 & 28.6 & 0.2 & 0.8 \\
\hline $5 \%$ vaporized vol. & 1.0 & 0.6 & 4.8 & 3.5 & 2.3 \\
\hline $10 \%$ vaporized vol. & 1.4 & 0.6 & 1.4 & 1.1 & 0.2 \\
\hline $20 \%$ vaporized vol. & 0.1 & 3.4 & 1.3 & 0.0 & 3.2 \\
\hline $30 \%$ vaporized vol. & 0.0 & 3.7 & 1.5 & 4.8 & 0.1 \\
\hline $40 \%$ vaporized vol. & 0.2 & 2.6 & 0.2 & 5.0 & - \\
\hline $50 \%$ vaporized vol. & 0.7 & 2.2 & 0.8 & 2.6 & 0.5 \\
\hline $60 \%$ vaporized vol. & 0.7 & 1.7 & 1.1 & 1.3 & - \\
\hline $70 \%$ vaporized vol. & 0.5 & 0.5 & 0.4 & 1.7 & 0.9 \\
\hline $80 \%$ vaporized vol. & 5.3 & 0.9 & 0.2 & 5.7 & 1.3 \\
\hline $85 \%$ vaporized vol. & 3.6 & 3.0 & 0.3 & 7.2 & - \\
\hline $90 \%$ vaporized vol. & 1.5 & 7.2 & 2.5 & 9.1 & 0.3 \\
\hline $100 \%$ vaporized vol. & 9.2 & 0.7 & 8.0 & 19.3 & 10.5 \\
\hline
\end{tabular}

${ }^{a}$ Heavy naphtha; ${ }^{b}$ kerosene; ${ }^{c}$ light diesel; ${ }^{d}$ heavy diesel; ${ }^{e}$ reduced crude oil.

Table 5. Absolute deviation between simulated and operational yields and relative densities with respect to water at $60^{\circ} \mathrm{F}$ (approximately $15.6^{\circ} \mathrm{C}$ or $288.7 \mathrm{~K}$ ).

\begin{tabular}{ccc}
\hline & \multicolumn{2}{c}{ Absolute deviation } \\
\hline Product & Yield (\%) & Density at $60^{\circ} \mathrm{F}$ \\
\hline $\mathrm{HN}^{\mathrm{a}}$ & 0.013 & 0.0043 \\
$\mathrm{KE}^{\mathrm{b}}$ & 0.044 & 0.0046 \\
$\mathrm{LD}^{\mathrm{C}}$ & 0.017 & 0.0001 \\
$\mathrm{HD}^{\mathrm{d}}$ & 0.009 & 0.0005 \\
$\mathrm{RCO}^{\mathrm{e}}$ & 0.007 & 0.0001 \\
\hline${ }^{\mathrm{a}}{ }_{\text {Heavy naphtha; }}{ }^{\mathrm{b}}$ $_{\text {kerosene; }}{ }^{\mathrm{c}}$ light diesel; &
\end{tabular}

operational data is expressed in the table with the deviations between these two data sets, as shown in Table 4. Both literature (Camões, 2014) and the company operating the column indicated $10{ }^{\circ} \mathrm{C}$ as the maximum acceptable value of temperature absolute deviation for a calibration. Values over this threshold were highlighted in Table 4, showing that almost all simulated data (59 out of 62) had acceptable absolute deviations.

The points with deviations over the acceptable limit are outside the range where a good prediction related to the section efficiency parameter is expected, i.e. from 10 to $90 \%$. Being just a fine tuning, the shape factors have difficulty to predict these points correctly. Density and yield data were also compared and their deviations were analyzed. Table 5 shows the absolute deviation between simulated and operational yields and densities.

Analyzing the table, it is possible to see that these properties were also well-modeled after calibrating the column. The small differences in the flow of any of the streams, which provoke the deviations in the yields, are too small considering 


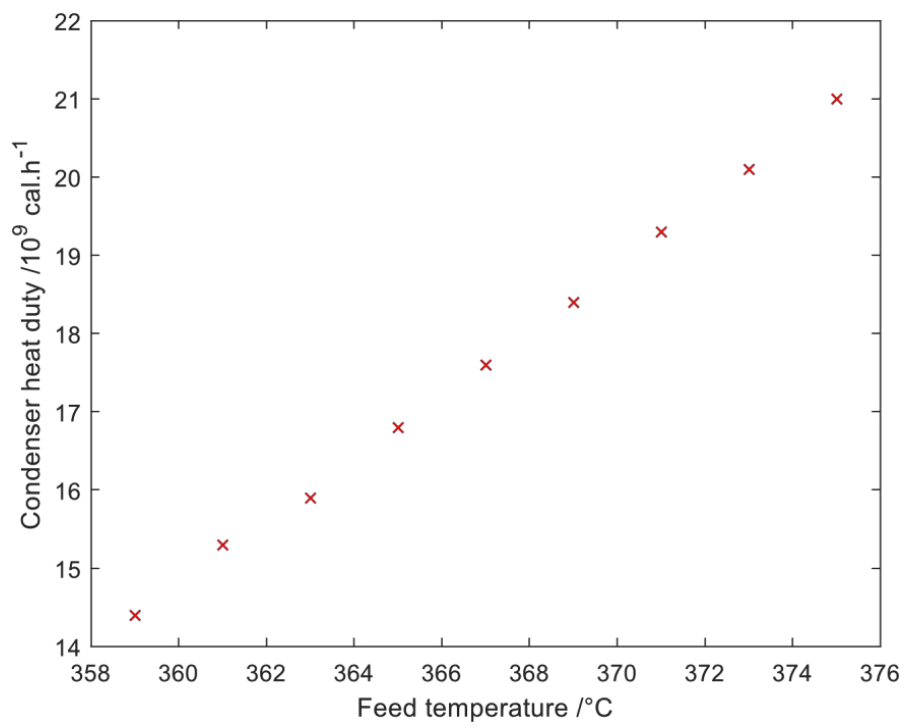

Figure 6. Top condenser heat duty as a function of the feed temperature with rectifying vapor flow of $351600 \mathrm{~kg} \cdot \mathrm{d}^{-1}$.

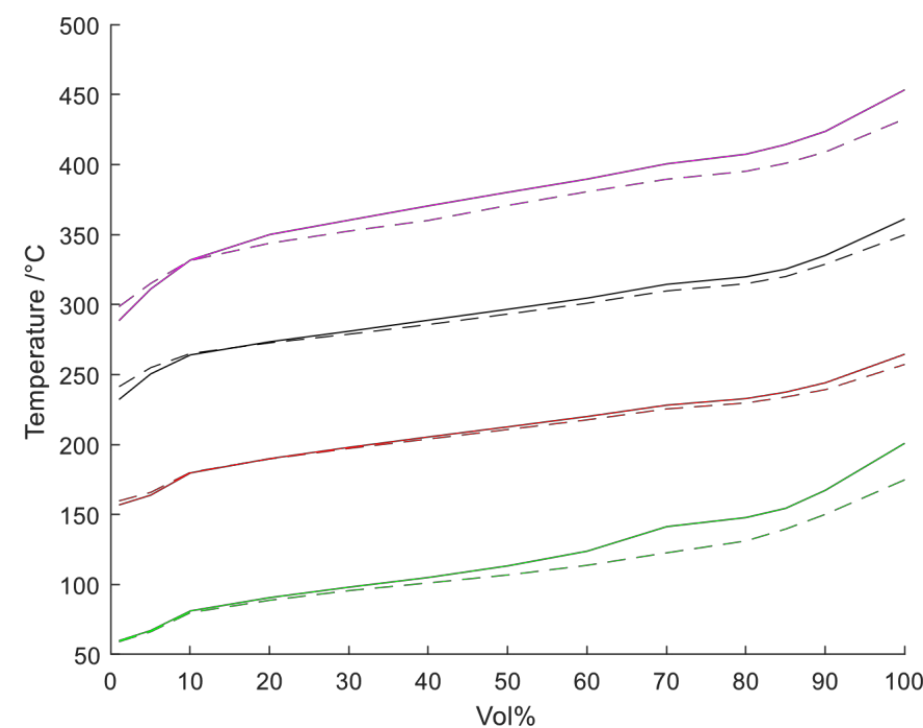

Figure 7. Simulated ASTM D86 distillation curves at the lowest and the highest feed temperatures with rectifying vapor flow of $351600 \mathrm{~kg} . \mathrm{d}^{-1}$. Green: HN; red: KE; black: LD; magenta: HD. Solid lines refer to data with feed at $359^{\circ} \mathrm{C}$. Dashed lines refer to data with feed at $370^{\circ} \mathrm{C}$.

the total flow of the stream, even for that with the highest deviation, i.e. the kerosene stream. Such deviation represents $0.4 \%$ deviation of the total stream. There was also a good agreement for density data.

\subsection{Sensitivity analysis}

The top condenser heat duty variation as a function of the feed temperature is shown in Figure 6 . The rectifying vapor flow is set at the operational plant value, $351600 \mathrm{~kg} \cdot \mathrm{d}^{-1}$.

As expected, the increase in feeding temperature promotes a condenser heat duty increase. When the feed temperature is increased while maintaining the other variables constant, there is an increase in the top column section temperature. To decrease this temperature to the regular value, it is necessary an increase in the top reflux flow. Consequently, the internal flows of liquid and vapor would be higher. As a higher amount of vapor would be cooled in the top condenser, its heat duty would be higher and more energy would be consumed.

Figure 7 shows the simulated ASTM D86 distillation curves of the products with the highest and the lowest feed temperatures. 


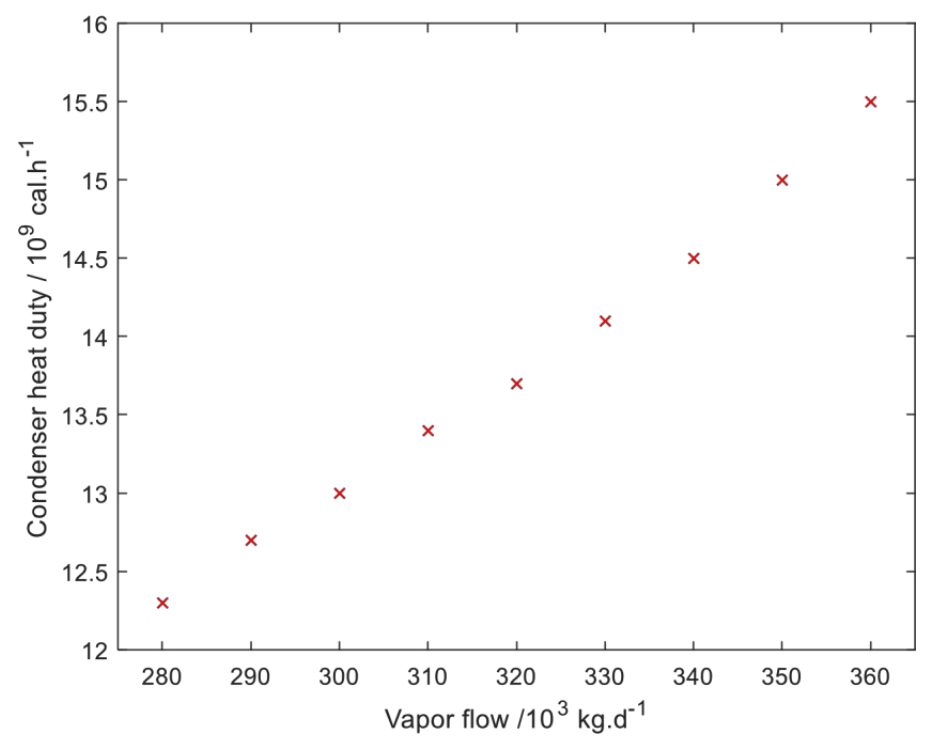

Figure 8. Top condenser heat duty as a function of the rectifying vapor flow with feed temperature of $360.6^{\circ} \mathrm{C}$.

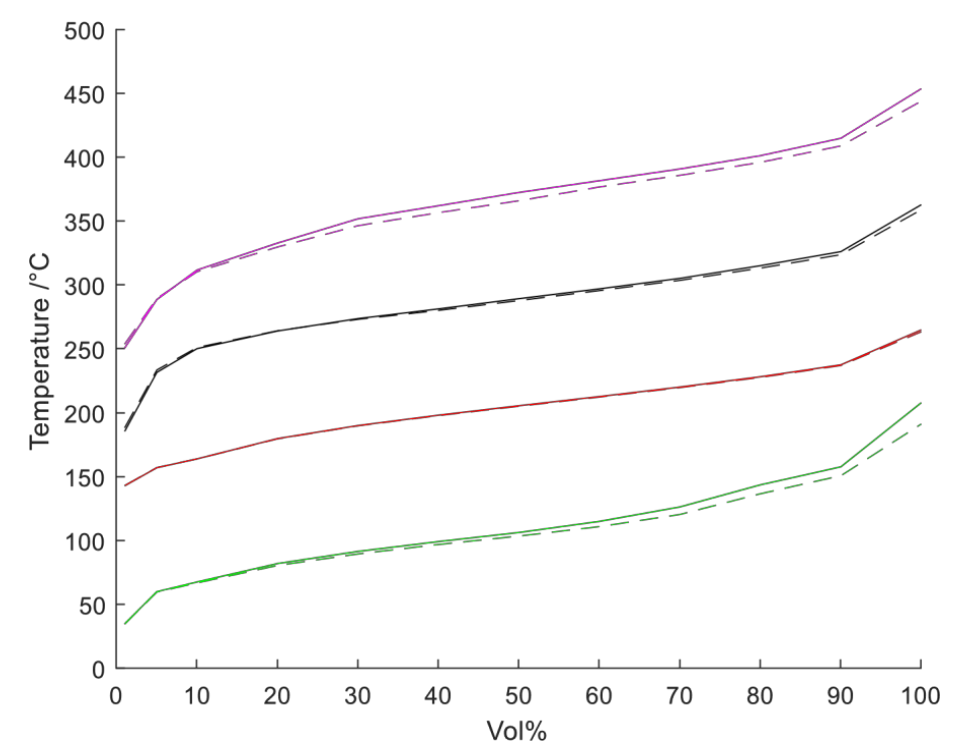

Figure 9. ASTM D86 distillation curves simulated at the lowest and the highest rectifying vapor flows with feed temperature of $360.6^{\circ} \mathrm{C}$. Green: HN; red: KE; black: LD; magenta: HD. Solid lines refer to data with rectifying vapor flow at $280000 \mathrm{~kg} \cdot \mathrm{d}^{-1}$. Dashed lines refer to data with rectifying vapor flow at $360000 \mathrm{~kg} \cdot \mathrm{d}^{-1}$.

It is possible to observe that the feed temperature influences product quality and its increase causes a decrease in the majority of distillation curves' temperatures for the same vaporized volume. This results from the increase of the top reflux flow, that generates more condensation of ascendant vapor and a better incorporation of light components to the products.

Figure 8 shows the top condenser heat duty variation as a function of the rectifying vapor flow. The feed temperature is set at the operational plant value, $360.6^{\circ} \mathrm{C}$.
In a similar way, the increase in the rectifying vapor flow causes a heat duty increase, because of the higher amount of vapor in the column top section. However, in this case, the effect of the injected vapor increase itself would also be added. The vapor flow increase causes a decrease in most distillation curves' temperatures for the same vaporized volume, because of the better light components incorporation to the products. Figure 9 shows the simulated ASTM D86 distillation curves of the products with the highest and the lowest rectifying vapor flows.

It is also noteworthy that the temperature has a 
Table $6.3^{2}$ Factorial design matrix with the top condenser heat duty as the response.

\begin{tabular}{cccc}
\hline & \multicolumn{2}{c}{ Variable } & Response \\
\hline Simulation & $\begin{array}{c}\text { Feed temperature } \\
/{ }^{\circ} \mathrm{C}\end{array}$ & $\begin{array}{c}\text { Rectifying vapor flow } \\
/ 10^{3} \mathrm{~kg} \cdot \mathrm{d}^{-1}\end{array}$ & $\begin{array}{c}\text { Condenser heat duty } \\
/ 10^{9} \mathrm{cal}^{-\mathrm{h}^{-1}}\end{array}$ \\
\hline 1 & $359(-1)$ & $280(-1)$ & 11.85 \\
2 & $359(-1)$ & $320(0)$ & 13.31 \\
3 & $359(-1)$ & $360(+1)$ & 14.74 \\
4 & $367(0)$ & $280(-1)$ & 14.63 \\
5 & $367(0)$ & $320(0)$ & 16.31 \\
6 & $367(0)$ & $360(+1)$ & 17.95 \\
7 & $375(+1)$ & $280(-1)$ & 18.01 \\
8 & $375(+1)$ & $320(0)$ & 19.67 \\
9 & $375(+1)$ & $360(+1)$ & 21.31 \\
\hline
\end{tabular}

Table 7. $3^{2}$ Factorial design matrix with the heavy naphtha final boiling temperature as the response.

\begin{tabular}{cccc}
\hline & \multicolumn{2}{c}{ Variable } & Response \\
\hline Simulation & $\begin{array}{c}\text { Feed temperature } \\
/{ }^{\circ} \mathrm{C}\end{array}$ & $\begin{array}{c}\text { Rectifying vapor flow } \\
/ 10^{3} \mathrm{~kg} \cdot \mathrm{d}^{-1}\end{array}$ & $\begin{array}{c}\text { Condenser heat duty } \\
/ 10^{9} \mathrm{cal}^{-1} \mathrm{~h}^{-1}\end{array}$ \\
\hline 1 & $359(-1)$ & $280(-1)$ & 216.98 \\
2 & $359(-1)$ & $320(0)$ & 206.64 \\
3 & $359(-1)$ & $360(+1)$ & 199.31 \\
4 & $367(0)$ & $280(-1)$ & 185.70 \\
5 & $367(0)$ & $320(0)$ & 183.61 \\
6 & $367(0)$ & $360(+1)$ & 180.24 \\
7 & $375(+1)$ & $280(-1)$ & 176.20 \\
8 & $375(+1)$ & $320(0)$ & 175.46 \\
9 & $375(+1)$ & $360(+1)$ & 174.91 \\
\hline
\end{tabular}

${ }^{a}$ Heavy naphtha.

greater influence than the vapor flow, for both the condenser heat duty and the products distillation curves. Another important observation is that the heavy naphtha final boiling temperature is more sensitive to variations in the selected variables.

\subsection{Factorial design}

Table 6 shows the $3^{2}$ factorial design matrix with the top condenser heat duty as the response.

Further study about the products' specifications for each of the 9 scenarios showed that the heavy naphtha final boiling temperature is the most sensitive parameter among the key points in the products' distillation curves. Furthermore, it was possible to notice that, in this range, whenever the heavy naphtha final boiling temperature is in agreement with the specifications, i.e. under $188^{\circ} \mathrm{C}$, the other products also are specified. Thus, the heavy naphtha final boiling temperature was considered as a key parameter to represent the product quality in the next steps of this work. Caution is needed when using the simulation previously developed in the prediction of the fractions final boiling temperature. Observing the calibration, the model overestimated this temperature for the heavy naphtha. Hence, if the simulation indicates this temperature being $188^{\circ} \mathrm{C}$, it should be enough to ensure that it is, in practice, under this threshold. Table 7 shows the $3^{2}$ factorial design matrix with the heavy naphtha final boiling temperature as the response.

The identification of the most significant factors was done through the Pareto chart. The factors 


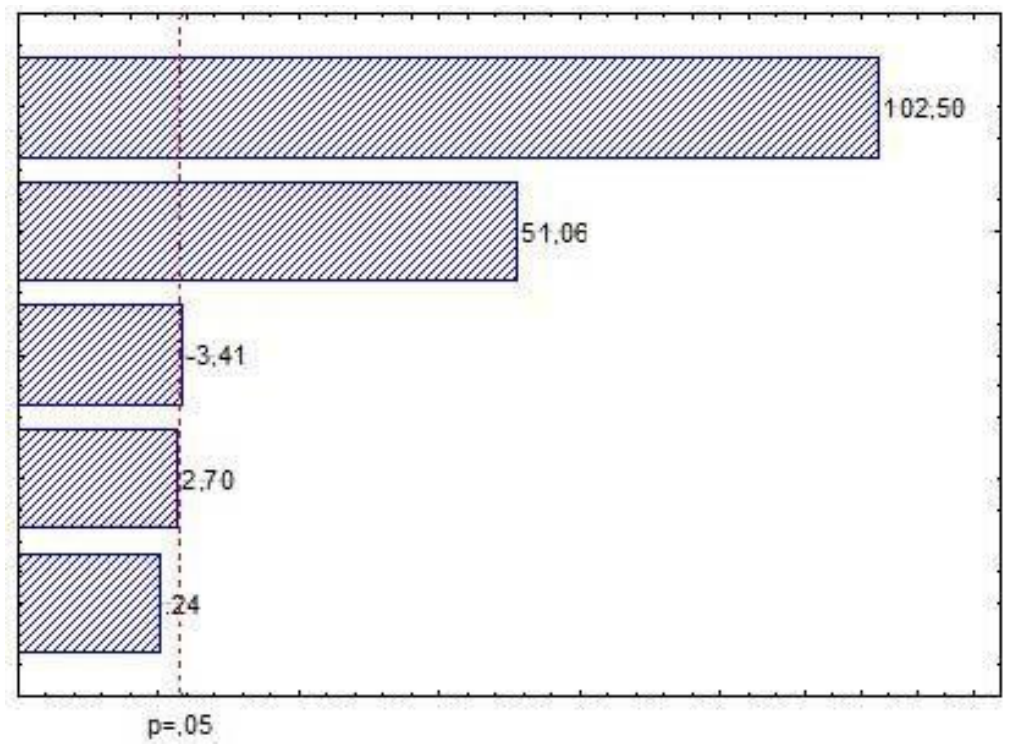

Figure 10. Pareto chart describing the variables effects on the top condenser heat duty. From top to bottom: feed temperature (linear); rectifying vapor flow (linear); feed temperature (quadratic); interaction between the linear effects of the feed temperature and rectifying vapor flow; rectifying vapor flow (quadratic).

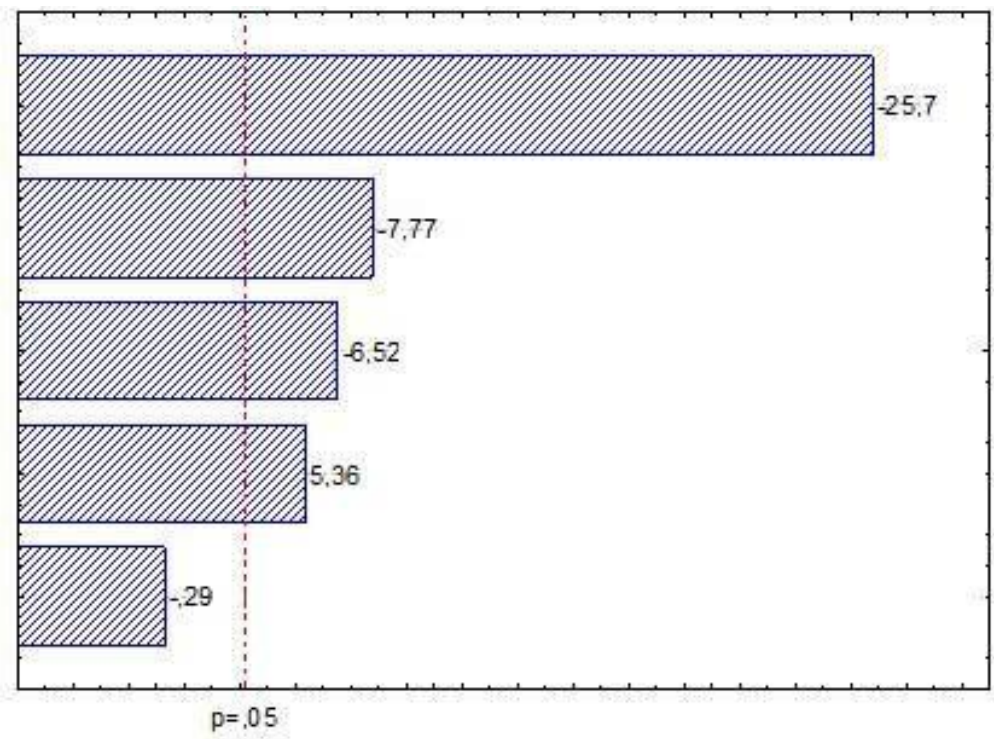

Figure 11. Pareto chart describing the variables effects on the heavy naphtha final boiling temperature. From top to bottom: feed temperature (linear); feed temperature (quadratic); rectifying vapor flow (linear); interaction between the linear effects of the feed temperature and the rectifying vapor flow; rectifying vapor flow (quadratic).

effects in the top condenser heat duty can be seen in Figure 10.

The values shown in the chart are the standardized effects of all factors and their interactions. Factors that cross the red dashed line are considered significant. Thus, the influence of feed temperature and vapor flow linear effects in the heat duty become clear. Feed temperature quadratic effect was also considered significant. It is important to notice that feed temperature linear effect is more pronounced than the vapor flow linear effect, which is in accordance with what was observed previously during the sensitivity analysis.

Factor effects on the heavy naphtha final boiling temperature can be seen in Figure 11. Regarding the heavy naphtha final boiling temperature, the chart shows that all evaluated effects and their interactions are significant, except by the vapor flow quadratic effect. In a similar way observing 


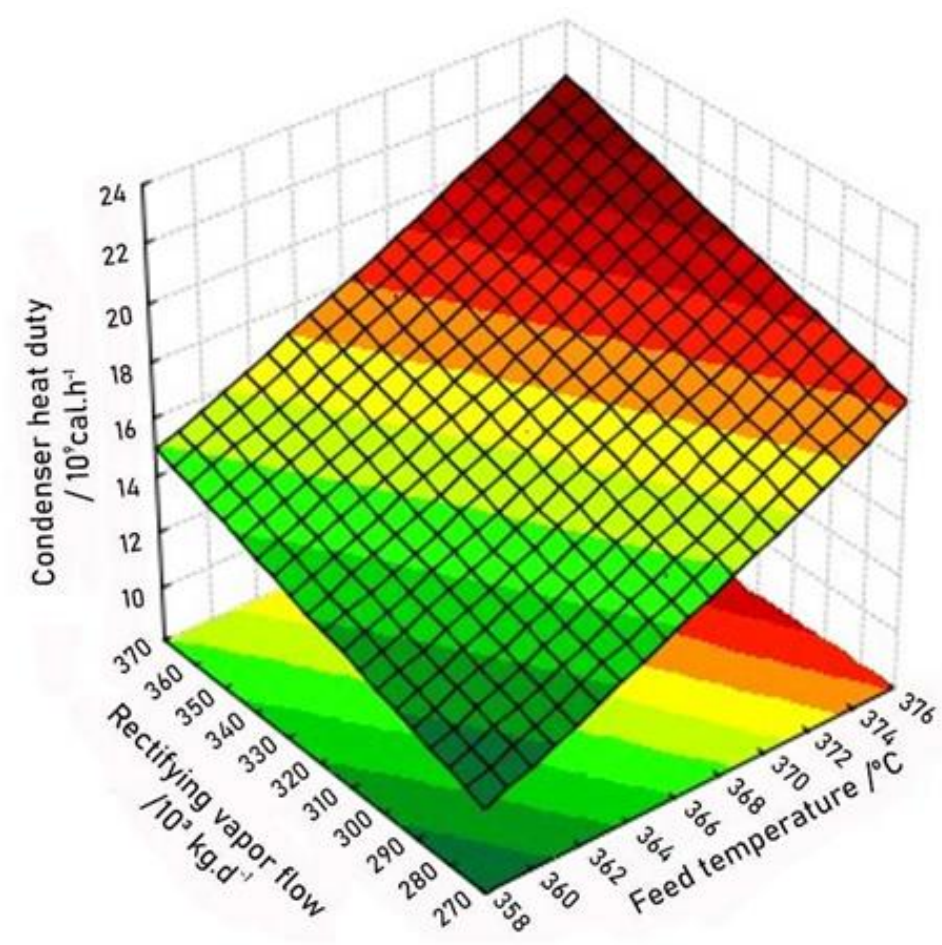

Figure 12. Response surface of the top condenser heat duty as a function of the feed temperature and the rectifying vapor flow.

the heat duty as response, one can notice that feed temperature linear effect is the most relevant factor. Hence, changes in this factor will promote a greater variation in product quality and in top condenser heat duty than if the vapor flow is changed.

\subsection{Mathematical model determination and validation}

Using STATISTICA and considering only the factors previously evaluated as significant, the mathematical models were determined and are presented in Equations (1) and (2):

$\mathrm{CHD}=244.0990-1.7081 \times \mathrm{FT}+2.8687 \times 10^{-3} \times$

$\times \mathrm{FT}^{2}+3.9608 \times 10^{-2} \times \mathrm{RVF}$

$\mathrm{FBT}=20124.0809-102.4381 \times \mathrm{FT}+1.3124 \times 10^{-1} \times$

$\times \mathrm{FT}^{2}-4.8003 \times \mathrm{RVF}+1.2803 \times 10^{-2} \times \mathrm{FT} \times \mathrm{RVF}$

where CHD is the top condenser heat duty, FT is the feed temperature, RVF is the rectifying vapor flow, and FBT is the heavy naphtha final boiling temperature.

Equation (3) represents the linear relation between the model data and the simulated data for the top condenser heat duty. Equation (4) represents the linear relation between the model data and the simulated data for the heavy naphtha final boiling temperature.

$\mathrm{CHD}_{\mathrm{M}}=0.9992 \times \mathrm{CHD}_{\mathrm{S}}+0.0129$

$\mathrm{FBT}_{\mathrm{M}}=0.9961 \times \mathrm{FBT}_{\mathrm{S}}+0.6944$

where the subscript $M$ refers to the model and the subscript $S$ refers to the simulated data.

One can observe that both equations fit the established criteria, with the angular coefficient being around 1 and the linear coefficient being around 0 . Furthermore, they had a $R^{2}$ greater than 0.99 , showing a good correlation.

From the models, it was possible to generate one response surface for each model. Figure 12 shows the response surface of the model with the top condenser heat duty as the response. 


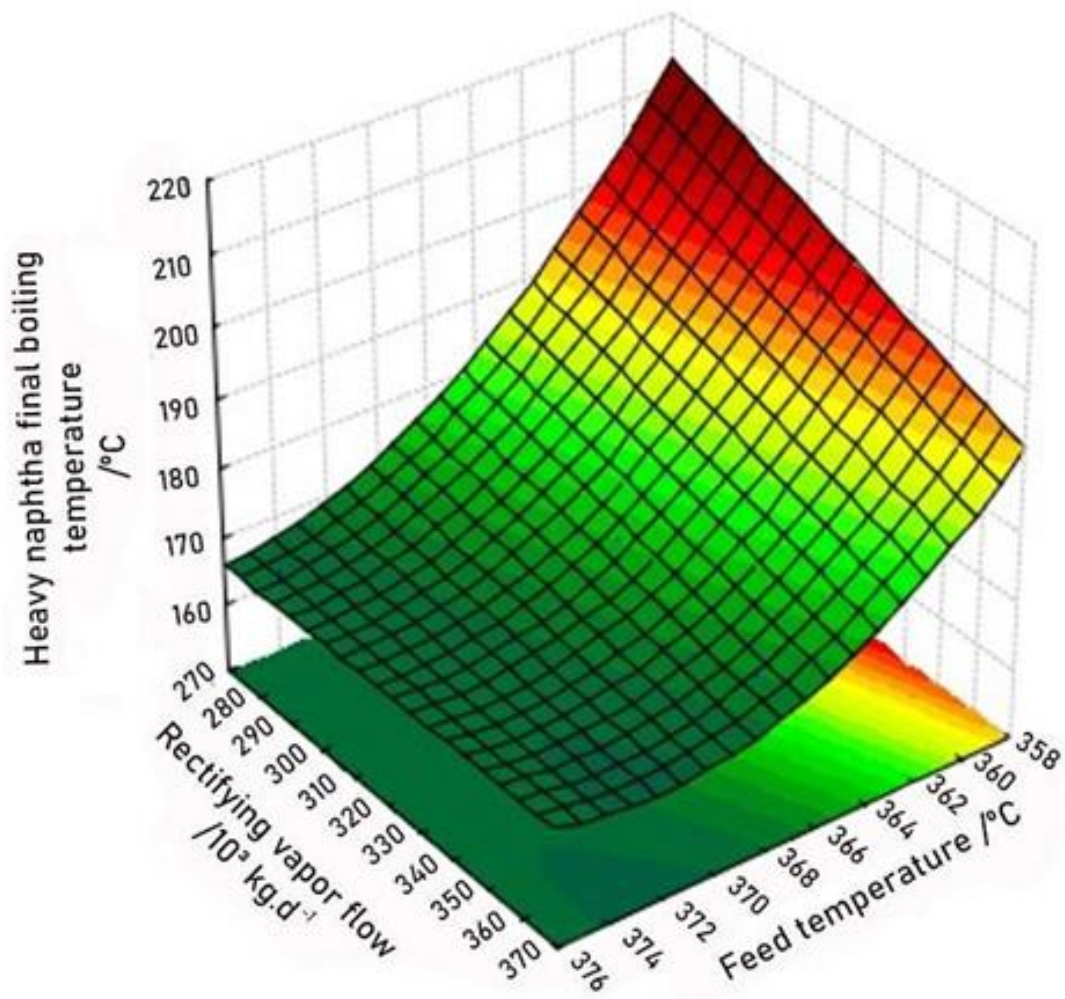

Figure 13. Response surface of the heavy naphtha final boiling temperature as a function of the feed temperature and the rectifying vapor flow.

The heat duty is reduced with the decrease of both independent variables, in agreement with what was observed in the previous steps of this work. This happens because the increase in the reflux flow, that occurs when the column has a higher feed temperature and rectifying vapor flow, generates more vapor at the column top section and, keeping the other variables constant, there is increase in the condenser heat duty. Another important feature that can be noticed in the response surface is its shape, showing a behavior almost entirely linear.

Figure 13 shows the response surface of the model with the heavy naphtha final boiling temperature as the response.

Different from the previous response surface, this one shows a decrease in the response if any of the factors is increased. Also, as stated before, the interaction between factors is relevant for this response and this fact can be seen clearly when comparing the variation of the response along low and high feed temperature regions. The response decreases with the vapor flow increase much more drastically when the feed temperature is higher. Furthermore, this surface presented an important quadratic behavior because of the feed temperature quadratic influence on heat duty.

Table 8. Optimization results.

\begin{tabular}{ccccc}
\hline & Default operation & S1 & S2 & S3 \\
\hline Feed temperature $/{ }^{\circ} \mathrm{C}$ & 360.60 & 359.65 & 363.64 & 363.64 \\
Rectifying vapor flow $/ 10^{3} \mathrm{kg.d}-1$ & 351.60 & 360.00 & 280.00 & 280.00 \\
Furnace heat duty $/ 10^{9}{\mathrm{cal} . \mathrm{h}^{-1}}^{-1}$ & 85.44 & 84.62 & 88.09 & 88.09 \\
Reboilers heat duty $/ 10^{9} \mathrm{cal}^{-1}$ & 8.94 & 9.15 & 7.12 & 7.12 \\
Condenser heat duty $/ 10^{9} \mathrm{cal}^{-1}$ & 15.12 & 15.11 & 13.41 & 13.41 \\
Total heat duty $/ 10^{9} \mathrm{cal}^{-1}$ & 109.51 & 108.88 & 108.62 & 108.62 \\
\hline
\end{tabular}




\subsection{Determination of optimal conditions}

With the models, it was possible to optimize the process for scenarios S1 to S3, as shown in Table 8. The results indicate that, for every scenario studied, there was an improvement in the top condenser heat duty and in the total heat duty. S2 and S3 showed less energy consumption when compared to S1. Also, S2 and S3 showed equal improvement. This means that the lowest top condenser heat duty is achieved minimizing the rectifying vapor flow. When comparing S1 to the default operation condition, a reduction of $0.58 \%$ in total heat duty is achieved. When comparing S2 and S3 to the default operation, the reduction is greater: $0.81 \%$. So, when there is no limitation in the heat duty provided by the unit furnaces, the optimal operational condition will have feed temperature of $363.64{ }^{\circ} \mathrm{C}$ and vapor flow of 280000 $\mathrm{kg} \cdot \mathrm{d}^{-1}$. The change from the default operational condition to this proposed condition would cause a reduction of $2148 \mathrm{~m}^{3}$ per month in water consumption and $8.9 \times 10^{8} \mathrm{cal} / \mathrm{h}$. Therefore, although the relative reduction seems like just a small energy saving, when the absolute energy saving is considered, it is possible to see how big the impact of the proposed optimization is. Moreover, taking into consideration all costs involved in energy production, its implementation would result in significant financial gains for the unit.

\section{CONCLUSION}

This work presents a full methodology for determining the optimal operational conditions of a real crude distillation unit column employed in petroleum refining in the Northeast region of Brazil. The modeling step detailed provides a proper representation in Petro-SIM simulation environment of the studied process.

The application of the Synthesize method to the unknown composition feed stream, using information from the products obtained after its fractionation, was successful, making the simulation feasible without having to input the feed composition. It was also possible to model and simulate the column properly. The success of the calibration can be verified by the good agreement with operational data in almost the whole range of the distillation curves, with absolute relative deviations under $10{ }^{\circ} \mathrm{C}$, except by some points in both ends of the curve. For all the cases, the points not well-adjusted were concentrated in the range where the model may not adjust with high precision due to its inherent characteristics. This behavior was already expected, as the shape factors act just as a fine tuning for both ends of the curves.

Therefore, one needs caution when using the simulation to predict properties related to these parts of the curves, like the flash point and the start and final boiling temperatures of each fraction. The simulation was overestimating the heavy naphtha final boiling temperature and the optimization considered this temperature should always be under $188 \stackrel{\circ}{\circ}$, so the method can be used in this case. Besides that, a good representation of the middle section of the distillation curves was achieved. There was also good agreement in yield and density data for all fractions studied.

Thus, after calibration, it was possible to use the atmospheric distillation column in the simulation environment as a proper representation of the actual column in the next steps of this work, as well as it is in future works and on the decisionmaking process in the refinery.

The manipulated variables selected were feed temperature and rectifying vapor flow. The sensitivity analysis showed that both the top condenser heat duty and the product distillation curves are more affected by variations in feed temperature than in vapor flow. Another fact observed was that the heavy naphtha boiling temperature can be used as an important parameter to determine if the products are specified and, therefore, are deemed quality products.

Through the factorial design, two $3^{2}$ matrices, one for the condenser heat duty and one for the heavy naphtha final boiling temperature, were made. Combining the factorial design, using calibrated simulation and Pareto charts, models were determined to represent the relationship between independent and dependent variables, considering only the factors determined as significant by the respective Pareto chart. For the condenser heat duty, feed temperature and vapor flow linear effects were identified as the most 
prominent, but with a small contribution of feed temperature quadratic effect. For the heavy naphtha final boiling temperature, all effects were significant, except for the vapor flow quadratic effect. The model validation was carried out successfully using the linear regression method.

The optimization was done with the aid of Microsoft Excel, analyzing three different scenarios: one with feed temperature restriction, one with vapor flow restriction, and one without restrictions. It was possible to achieve energy consumption reduction in all three scenarios, with the last two presenting the same optimal operational conditions. These changes caused a reduction of $0.81 \%$ in the condenser heat duty. In spite of achieving apparent extremely low energy savings, it would represent a monthly reduction of $2148 \mathrm{~m}^{3}$ in water consumption. This study was done considering the unit operating with the most used crude oil in the refinery; a study with different oils could lead to different results. Although, the work shows the possibility of using the use of the same methodology for any other petroleum feed, the capacity of statistical methods to be employed as an optimization tool, the value of the association of statistics and process simulation, and a deeper insight in the Distop method, scarcely approached in the literature.

\section{ACKNOWLEDGMENTS}

The authors acknowledge the financial support from FAPESB/SECTI-BA and CNPq. This study was also supported by the Coordenação de Aperfeiçoamento de Pessoal de Nível Superior Brasil (CAPES).

\section{REFERENCES}

ASTM International (2016). ASTM D86 - 16a Standard Test Method for Distillation of Petroleum Products and Liquid Fuels at Atmospheric Pressure. Available at https://www.astm.org/Standards/D86.htm. Access in $07 / 12 / 2017$.
Camões, T. G. Modelação de uma Coluna sob Vácuo da Refinaria de Sines. 101f Dissertação de Mestrado. Técnico Lisboa, Lisboa, Portugal, 2014. (in Portuguese).

Gu, W.; Wang, K.; Huang, Y.; Zhang, B.; Chen, Q.; Hui, C. Energy optimization for a multistage crude oil distillation process. Chemical Engineering \& Technology, v. 38, p. 1243-1253, 2015. https://doi.org/10.1002/ceat.201400130

Javaloyes-Antón, J.; Ruiz-Femenia, R.; Caballero, J. A. Rigorous design of complex distillation columns using process simulators and the particle swarm optimization algorithm. Industrial \& Engineering Chemistry Research, v. 52, p. 15621-15634, 2013.

https://doi.org/10.1021/ie400918x

KBC Advanced Technologies. Petro-SIM ${ }^{\mathrm{TM}}$ Refining and Petrochemicals. Guide: Distop Model. Access in 07/12/2017.

Kim, B. C.; Chun, H. H.; Kim, Y. H. Energy-efficient diabatic distillation using a horizontal distillation column. Industrial \& Engineering Chemistry Research, v. 52, p. 14927-14935, 2013. https://doi.org/10.1021/ie4013997

Kiss, A. A. Distillation technology - still young and full. Journal of Chemical Technology and Biotechnology, v. 89, p. 479-498, 2014. https://doi.org/10.1002/jctb.4262

Mahdi, K.; Gheshlaghi, R.; Zahedi, G.; Lohi, A. Characterization and modeling of a crude oil desalting plant by a statistically designed approach. Jornal of Petroleum Science and Engineering, v. 61, p. 116-123, 2008.

https://doi.org/10.1016/j.petrol.2008.05.006

Montgomery, D. C.; Runger, G. C. Applied Statistics and Probability for Engineers (3rd edition). New York, NY: John Wiley \& Sons, Inc, 2003.

Motlaghi, S.; Jalali, F.; Ahmadabadi, M. N. An expert system design for a crude oil distillation column with the neural networks model and the process optimization using genetic algorithm framework. Expert Systems with Applications, v. 35, p. 1540-1545, 2008.

https://doi.org/10.1016/j.eswa.2007.08.105 
Ochoa-Estopier, L. M.; Jobson, M.; Smith, R. Operational optimization of crude oil distillation systems using artificial neural networks. Computers and Chemical Engineering, v. 59, p. 178-185, 2013. https://doi.org/10.1016/i.compchemeng.2013.05.030

Rodrigues, M. I.; lemma, A. F. Planejamento de Experimentos e Otimização de Processos. Campinas: Casa do Pão Editora, 2005.

Sousa, C. B.; Gomes, V. A.; Lucena, S. M. Otimização energética de colunas de destilação atmosférica e a vácuo para petróleo em função do ${ }^{\circ} \mathrm{API}$ da carga. In: XX Congresso Brasileiro de Engenharia Química, 2014. Proceedings XX Congresso Brasileiro de Engenharia Química. Florianópolis, COBEQ, 2015. (in Portuguese). https://doi.org/10.5151/chemeng-cobeq2014-113420816-160934

Souza, M. R.; Pinho, S. P.; Guimarães, P. R. B.; Vianna, R. F. Selection of optimal operating conditions based on minimum energy consumption for an acrylonitrile recovery unit. Separation Science and Technology, v. 51, p. 1830-1839, 2016. https://doi.org/10.1080/01496395.2016.1182188
Szőke-Kis, A.; Farkas, C. I.; Mizsey, P. Comprehensive Investigation and Comparison of Refinery. Industrial \& Engineering Chemistry Research, v. 53, p. 19282-19292, 2014. https://doi.org/10.1021/ie502807x

Taqvi, S. A.; Tufa, L. D.; Muhadizir, S. Optimization and dynamics of distillation column using Aspen Plus ${ }^{\circledR}$. Procedia Engineering, v. 148, p. 978-984, 2016.

https://doi.org/10.1016/i.proeng.2016.06.484

Yang, N. S.; Chuang, K. T. A new criterion for modeling distillation column data using commercial simulators. Industrial \& Engineering Chemistry Research, v. 39, p. 33083313, 2000. https://doi.org/10.1021/ie990821g 